\title{
Primigravida Women's Fear of Childbirth and Its Effect on Their Decision Regarding Mode of Delivery
}

\author{
Bahaia Ali Mohammed Osman', AzzaFouad Mohammed El-Adham², \\ Aleya Mohamed Elrefaey ${ }^{3}$. \\ ${ }^{1}$ Specialist nursing in Kom Hamade General hospital, ${ }^{2}$ Assistant \\ Professor, ${ }^{3}$ Lecturer, ${ }^{2,3}$ Maternity and Gynecological Nursing, Faculty of Nursing, Tanta \\ University, Tanta, Egypt
}

\begin{abstract}
Background: Fear or phobia of childbirth is a significant distressing psychological disorder encountered among $14 \%$ of women of childbearing age. It is known as Tokophobiamaleusiophobia and parturiphobia. It is more common among primigravida women and can influence their decision on the mode of delivery. Little attention has been given to primigravida women's fear of childbirth and its effect on their decision regarding mode of delivery. The aim of this study: was to assess primigravida women's fear of childbirth and its effect on their decision regarding the mode of delivery. Subjects and Method: The study was conducted in Egypt at 3 outpatient clinics of Obstetric and Gynecological Departments of Tanta University Hospital, El-Menshawy General Hospital and Kom-Hamade General Hospital (Ministry of Health and Population). Convenient subjects of 240 women who fulfilled the inclusion criteria were included in this study. They were selected from the previously mentioned settings, (80) from each setting. Five tools were developed and used to collect the study data: Tool (I): Socio-demographic and reproductive structured interview schedule. Tool (II) pregnant women fear of childbirth questionnaire. Tool (III) Anxiety scale for pregnancy (ASP). Tool (IV): Beck Anxiety Inventory were used to measure primigravida women's level of anxiety and its effect on pregnant women' body. Tool (V): Pregnant women's decision on the mode of delivery. Results: The results of the present study revealed that primigravida women experienced various levels of fear of childbirth that effected their decision regarding mode of delivery. Conclusion and recommendations: Primigravida women experienced high level of fear of childbirth. Thus, it is recommended that providing comprehensive antenatal care including psycho-educational nursing intervention, especially for primigravida and their husbands or partners is very important.
\end{abstract}

Keywords: Fear, Phobia, Anxiety, Fear of childbirth, cesarean section, Primigravida 


\section{Introduction}

Pregnancy and childbirth are considered as a matter of life and death especially, in places with limited resources. Modes of delivery could be normal vaginal delivery or cesarean section. God has gifted humans with normal vaginal delivery from the beginning of Adam's creation, to have children for continuation of the humanity. Vaginal delivery is a spontaneous process that needs no intervention, while cesarean section (CS) is done only when natural delivery is contraindicated to save mothers and infant's health and life ${ }^{(1-2)}$.Pregnancy is especially a personal experience that inspires a wide range of reactions that varies from very positive to negative ones due to complexity of this process. Primigravida women fear of childbirth can be influenced by many factors, such as fear of pain, fear of loss of control during delivery, fear of uterine rupture, fear of operative delivery and fear of having an impaired or stillborn infant. Predisposing factors to primigravida fear of childbirth include young maternal age, null parity, preexisting psychological issues, inadequate social support and history of abuse, family history of difficult obstetric procedures, as well as different physical and psychological changes that occur in woman's body for adaptation to the growing fetus during pregnancy ${ }^{(3,4)}$.

Childbirth is a unique dynamic process that affects every aspect of women's life. It is considered as a multi-dimensional experience that includes physical, emotional, psychological, developmental, social, cultural, and spiritual elements. Childbirth is considered as the happiest action occurred in any parent's life. Ifpregnancy is accompanied by high levels of fear and anxiety,it will become a traumatic experience for primigravida women ${ }^{(5,6)}$.Fear of childbirth is known as phobia of childbirth, Tokophobia, maleusiophobia and parturiphobia. It is a psychological disorder that causes significant distress or impairment of personal functioning. Behavioral or mental signs and symptoms may be persistent, relapsing and remitting, or occur as a single episode. Fear of childbirth is encountered among $14 \%$ of (1 out of 5) pregnant women. Additionally, approximately 6-13\% experience severe and debilitating fear. Pregnant women experience fear of childbirth for many reasons including fear of injury to self, baby, or death ${ }^{(1,6)}$.

A phobia also refers to a specific type of anxiety disorder that involves a persistent and excessive rapid onset of fear of an 
object or situation. This fear may presents for more than six months leading the women to avoid normal vaginal delivery or to have stress if it is unavoidable So, there is no comprehensive definition for the fear of childbirth. Instead of the advances in obstetrics, and the decrease of perinatal morbidity and mortality of the mother and neonate especially in the developed countries, nearly $80 \%$ of pregnant women still have fear, anxiety, or worry of childbirth ${ }^{(1,7,8)}$.Phobias ratios varied by age and gender. Women are nearly four times as likely as men to have a fear. It is most common mental illness among Americans women in all age estimated that constitute between 8.7 percent and 18.1 percent. Fear or phobia is classified into three types that include specific phobia, social phobia, and agoraphobia. Specific phobia is related to certain animals, environmental situations, and specific situations, such as fear of childbirth. Social phobia is a fear and anxiety from a situation due to critic of other individuals. Agoraphobia is a fear of a situation due to a difficulty or inability to avoid such situation ${ }^{(7,9)}$.

It is estimated that specific phobias affect about $6-8 \%$ of the western world individuals, and $2-4 \%$ in Asia, Africa, and Latin America. Social phobia affects about $7 \%$ of the United States individuals in and $0.5-2.5 \%$ of people worldwide. Agoraphobia affects about $1.7 \%$ of the people. Phobias impact women about twice as often as men. The onset of a phobia is around the ages of 10-17, and the rate decrease with increasing age $^{(9)}$.Fear, anxiety, and pain are the three factors that play a key role at the time of delivery, and during pregnancy. There are, approximately 140 million births occur globally every year, more than 4 million occurs in the United States and nearly 120 million in less developed countries. In Egypt, the annual number of births constitutes 28.8 births $/ 1,000$ populations according to the United Nations Populations Fund (UNFPA) statistics in 2019. Egypt stands out among countries with the highest CS delivery rates in the world, as well as among the Arab countries at a rate of 52 percent, followed by Brazil (55.6\%) and Dominican Republic $(56.4 \%){ }^{(10,11)}$.

Certain level of childbirth fear can be perceived and experienced as a normal, protective psychological aspect of pregnancy and childbirth that may help a pregnant woman to prepare for and resolve challenging childbirth issues during pregnancy, but more of childbirth fear is traumatic especially for primigravida. Primigravida women are more prone to childbirth fear and may 
experience more adverse pregnancy outcomes than multigravida (12). Childbirth fear levels are high in early and late pregnancy, especially among primigravidas. Primigravida women are those who have pregnancy for the first time. The birth of the first child is mainly categorized as an extremely psychosocial stressful. Consequently, primigravidas are more prone to childbirth fear and may experience more adverse pregnancy outcomes than women who have given birth before ${ }^{(2,12)}$.

The World Health Organization (WHO) standards recommend that every pregnant woman should receive psychological support to strengthen her capability of giving birth. Nowadays, unfortunately, CS has become a culture for escaping from fear and pain of childbirth. Consequently, it influenced the overall health and increases cost for both the family and the community ${ }^{(8)}$.CS also put more risk to the mother and her newborn compared to vaginal delivery. It includes complications for the mother, such as bleeding, thromboembolism, preterm labor and increased mortality rate. It also includes complications for the newborn, as respiratory distress syndrome, resistant pulmonary hypertension, and damages like injury, bruise, or other traumas ${ }^{(13,14)}$.
The birth of the first child is mainly categorized as an extremely stressful event and psychosocial stressor. Primigravida are regarded as a high-risk and crucial group who needs regular assistance in terms of antenatal, natal and post-natal care. Unluckily, much importance is not given to this group of women's health due to many factors. The main factors behind this are lack of education especially health education, lack of provision of health services, lack of awareness, regarding importance of antenatal care, lack of proper referral system resulting in mismanagement of primigravida during antenatal and postnatal period ${ }^{(13,15,16)}$. In some cases, religious and cultural factors in the community are responsible for improper antenatal care. It is found that lower income, education, economic status, occupational position and ignorant about mode of delivery are accompanied by high level of fear of childbirth. In turn, this made them seeking CS without medical indication. Thus, it was critical to assess fear of childbirth among primigravida women and its effect on their decision toward mode of delivery $^{(17,18)}$.

Unfortunately, cesarean section is one of the most frequently performed operations among women. Nowadays, there is an 
increase in the cesarean section (CS) rates over the world instead of the improvement and access to obstetric care. Furthermore, CS is one of the modern delivery options done by obstetricians, becauseit is considered easier mode of delivery. Hence CS rate is a major public health problem for mothers and babies, as well as it increase the cost outcome compared tonormal deliveries. The rate of caesarean section (CS) has been increasing among women in Egypt. A recent study documented that Egypt ranked the $3^{\text {rd }}$ among world countries with an estimated rate of cesarean section of $51.8 \%$. This skyrocketing rate is probably related to a mixture of reasons. The increased maternal request for cesarean section especially in primigravida without medical rationales and justification, but due to fear of childbirth $^{(19,20)}$.

The dramatic increase in CS rates globally has prompted concerns that the procedure may be overused or used for inappropriate indications. In addition, cesarean section is a major surgery with many complications. CS carries with it all the risks associated with surgery combined with the risks of birth itself. A woman who is delivered by cesarean section has a higher maternal mortality rate than is a woman who delivers vaginally. Whereas approximately 2.1 per 100,000 women die during a vaginal birth, while the mortality rate is 5.9 per 100,000 for women who undergo an elective cesarean birth and 18.2 per 100,000 for women who undergo an emergency cesarean birth. In Egypt, cesarean section is considered the direct cause of $7 \%$ of maternal deaths according to the Egypt national maternal mortality study in 2000. In Tanta University hospital, Rakhaet al, (2007-2009) found that one of the most common causes of maternal mortality are cesarean section complications, responsible for $19.05 \%$ of all deaths ${ }^{(21-23)}$.

Decision of the mode of delivery is defined as choosing either vaginal or caesarean section (C-section) delivery ${ }^{(24,25)}$.Pregnant women expressed a desire to be involved in the process of decision making, but not all of them actively participated. Some only became aware that a decision about how to deliver is needed to be made during the course of the pregnancy, while others were fully aware of the decision and choices available from the start. Many pregnant women admitted that a decision could never be final because of many factors can influence their decision, such as medical and social circumstances. The factors that can influence a woman's decision-making process related to choice 
of the mode of delivery are classified as maternal, baby, socio-demographic, the cultural values, social support, women's knowledge and attitude, decision of the health care provider, as well as their fear of childbirth proved to be a strongly connected factor for requesting cesarean section delivery ${ }^{(25,26)}$.

Fear of childbirth that may lead them to make incorrect decision. The health and wellbeing of both the mother and the baby are the major concerns of all pregnant women. Women's interactions with their health care providers regarding selection of birth method vary. They may be passive decision-makers or they may share decision-making related to mode of delivery with their health care providers So, they have the right to be informed of alternative birthing options, and risks associated with them. Evidence reports that pregnant woman who is knowledgeable about her condition can be able to deiced, which option is appropriate for herself and the fetus condition ${ }^{(25-27)}$.

\section{Aim of the Study}

The aim of this study was to: assess primigravida women's fear of childbirth and its effect on their decision regarding the mode of delivery

Research Question:
What is the effect of fear of childbirth among primigravida women on their decision regarding mode of delivery?

\section{Subjects and Method}

\section{Study Design}

A descriptive research design was adopted to conduct this study.

\section{Setting}

This study was carried out in Egypt at 3 outpatient clinics of obstetric and gynecological departments of the following hospitals:

-Tanta University Hospital

- El-Menshawy General Hospital

-Kom-Hamade General Hospital affiliated to Ministry of Health and Population.

\section{Subjects}

Convenient subjects of 240 women were included in this study. They were selected from the previously mentioned settings (80) from each setting. according to the following inclusion criteria: Primigravida , age 18-38 years, with normal pregnancy course, gestational weeks 30 and more, singleton pregnancy, are not health professionals, no past or present history of medical disorder, and willing to participate in the study.

\section{Tools of data collection:}

Five tools were used by the researcher to obtain the necessary data as the following: 
Tool (I): Women socio-demographic and reproductive history interview questionnaire sheet: It consisted of two parts as follow:

\section{Part (1): Socio-demographic data of the}

subjects: It was used to collect data about age, age at marriage marital status, residence, level of education, occupation, number of family members and family's income.

Part (2): Reproductive history: It was used to collect data about: date of last menstrual period (LMP), duration of current pregnancy (gestational weeks), antenatal booking (time and reasons of initial antenatal care visit), place of antenatal care, number of antenatal visits, attendance of antenatal care classes, and expected date of delivery (EDD).

Tool (II): Pregnant women's fear of childbirth questionnaire: This tool was adapted from Wijma Delivery Expectation / Experience Questionnaire (WDEQA $^{(28,29)}$. W-DEQ is a selfassessment scale containing 12 items to measure primigravidas fear of childbirth, such as frightful, afraid, weak, panic and hopelessness. The scores were calculated by the sum of the items as follows :Zero representing not at all or mild, Moderate $=1$,Severely $=2$

Total scoring system:
The total score for pregnant women's fear of childbirth questionnaire was calculated as follows:

- High level of fear $\geq 75 \%$.

- Moderated level of fear 60 - 75\%.

- Low level of fear $<60 \%$.

Tool (III): Anxiety scale for pregnancy (ASP)

This tool was adapted by the researcher guided by Doyle-Waters (30,31) \{The Anxiety Scale for Pregnancy (ASP) \}. It was used to measure primigravida women's anxiety. The ASP has 14 items, with higher scores indicating severe anxiety. The instrument has five subscales covering the following dimensions of pregnancy: the baby, labor, marital, attractive, and support. It included questions Such as: I feel relaxed about the health of my baby, I feel nervous thinking about the pain of childbirth, I feel worried that I won't get my figure back after my baby is born, I feel secure that the people I know care about me and will help me, and I feel concerned about losing control during labor. The scores were calculated by the sum of the items as follows: Not at all $=0$ , Mildly $=1$, Moderately $=2$, and Severely $=3$.

Total scoring system:

- No anxiety $=0-7$

- Mild level of anxiety $=8-15$ 
- Moderate level of anxiety $=16-25$

- Severe level of anxiety $=26-42$

\section{Tool (IV): Beck Anxiety Inventory}

This tool was adapted by researcher guided by Beck A, Epstein N, and Steer A, $1988^{(32,33)}$ to measure clinical anxiety. This scale consisted of 20 items, which covered the most common symptoms of anxiety. Each phrase reflected one of the symptoms of anxiety that people who are clinically anxious or who are in a state of great anxiety experience. The scores were calculated by the sum of the 20 items as follows: Not at all = 0 ,Mildly: but it didn't bother me much $=1$, Moderately: it wasn't pleasant at times $=2$, Severely: it bothered $\mathrm{me}=3$

Total scoring system:

- Low level of anxiety $=0-21$

- Moderate level of anxiety $=22-35$

- High level of anxiety $\geq 60$

\section{Tool (V): Pregnant women's decision}

\section{on the mode of delivery}

This tool was developed by researcher after reviewing relevant literatures ${ }^{(34,35,36)}$ to evaluate primigravida' decision toward mode of delivery. It composed of 20 items related to knowledge, attitude and preferences of pregnant women regarding mode of delivery, such as vaginal delivery is natural and accepted mode of delivery, vaginal delivery is better in long term, cesarean section is preferred in absence of economic problem, preferred birth type, main reason of choosing cesarean section is fear, and I lack of knowledge about normal vaginal delivery.The scores were calculated by the sum of the items as follows: $\mathrm{Bad}=0$, Neutral: it didn't bother me much $=1$, Good: it bothered me $=3$

Scoring system:

- Good decision on the mode of delivery $=\geq 75 \%$.

- Neutral decision on the mode of delivery $=60-75 \%$.

- Poor decision on the mode of delivery $<60 \%$.

\section{Method}

\section{Administrative approval}

Official letters were obtained from the Faculty of Nursing Tanta University and submitted to the responsible authority of the study settings to obtain their permission before conduction of the study.

\section{Ethical consideration}

- Approval of the ethical committee of the Faculty of Nursing Tanta University was obtained.

- The researcher met with the pregnant women individually and invited them to participate in the study after explanation of the purpose of the study. 
- Oral informed consent to participate in the study was obtained from the entire subjects.

- The researcher insured that the nature of the study will not cause any harm and/or pain for the entire subjects.

- Confidentiality and privacy were put into consideration regarding the data collected date.

\section{Developing the tools}

Five tools were developed to collect the study data. They were translated into the Arabic language and tested for the content and construct validity by five experts in the field of Obstetrics and Gynecological Nursing and the necessary modifications were carried out accordingly. The reliability of the tools was tested using appropriate statistical test analysis. Then, they were used as follows:

Tool (I): part (1) used to collect sociodemographic data of the subjects and part (2) to assess their reproductive history.

Tool (II) used to measure primigravida women fear of childbirth.

Tool (III) And Tool (IV): were used to measure primigravida women's level of anxiety and its effect on pregnant women' body.
Tool (V): used to assess pregnant women's decision on the mode of delivery.

\section{The pilot study}

A pilot study was carried out before the actual study on $10 \%$ of the sample (24 primigravida women) from Tanta university hospital, El-Menshawy hospital and Kom-Hamade General Hospital (Ministry of Health). It was conducted to test the clarity, feasibility and applicability of the different items of the study tools. Data obtained from the pilot study were excluded from the current study data. Based on the results of the pilot study, the necessary modifications were done by the researcher before conduction of the actual study.

\section{The actual study (field work):}

- The study data were collected from a convenient sample of 240 cases over a period of five months from the beginning of October 2019 to the end of February 2020 from the previously mentioned settings.

Data collection was conducted at the morning, and afternoon shifts until the predetermined sample size were collected. All cases presented at the time of data collection and have the inclusion criteria at each setting were included in 
the study. Data were collected by using the pre-developed tools.

\section{Statisticalanalysis of the data}

Data were fed to the computer and analyzed using IBM SPSS software package version 20.0. (Armonk, NY: IBM Corp) Qualitative data were described using number and percent Quantitative data were described using mean, standard deviation. Significance of the obtained results was judged at the $5 \%$ level. Chi-square test was used for categorical variables, to compare between different groups. Monte Carlo correction was used when more than $20 \%$ of the cells have expected count less than 5 . Pearson coefficient was used to correlate between two normally distributed quantitative variables. Regression was used to detect the most independent/ affecting factor for affecting mode of delivery and anxiety. And Cronbach's Alpha test was used to assess reliability of the tools of the study.

\section{Results}

Table (1): Illustrates the sociodemographic characteristics of the studied primigravida women. It was observed that the $69.6 \%$ of the studied primigravida women' age at marriage was $20-<30$ years with a mean and $\mathrm{SD}=22.63 \pm 3.59$, the majority of them were in the age group of $18-25$ years $(76.7 \%)$, while
$(18.3 \%)$ of them were in age group of more than (25 to 30 ), and only about (5\%) of them in the age group of more than 30 to 38 . The table also reveals that about $(40.8 \%)$ of them do not read or write, $(25 \%)$ have secondary education and $(11.7 \%)$ have university education or more. The table also shows that the majority of the studied primigravida women were from rural areas (84\%), while $(15.8 \%)$ of primigravida women were from urban areas. As regards to primigravida women working, it was observed that majority of them $(67.7 \%)$ were not working, while $(32.5 \%)$ of them were working. Finally the mean and SD of their family members was $5.06 \pm 3.60$.

Table (2): Presents that $(77.9 \%)$ of the studied primigravida women had moderate level of anxiety, nearly one fifth of them (17.9\%) had severe anxiety and only (4\%) had mild level of anxiety according to anxiety scale of pregnancy with a Mean \pm $\mathrm{SD}=52.67 \pm 9.43$.

Table (3): Shows total score of the studied primigravida women's anxiety of childbirth according to Beck anxiety inventory. It indicates that $(49.6 \%)$ has high level of anxiety, (49.6\%) has moderate level of anxiety and $(0.8 \%)$ has low level of anxiety, with a mean and standard deviation $=(34.08 \pm 6.35)$. 
Table (4): Presents the multivariate linear regression of the effect of fear of childbirth on primigravida women's decision on the mode of delivery. It reveals that fear of childbirth has a significant effect on the decision of primigravida women toward normal vaginal delivery $(\mathrm{F}=-4.817 *$, $\mathrm{p}=0.029$ ), while there it has no significant effect on their decision toward cesarean section mode of delivery $(\mathrm{F}=0.723$, $\mathrm{p}=0.396)$.

Table (5): Confirms the multivariate linear regression of the effect of anxiety of childbirth on the studied primigravida women's decision on the mode of delivery according to anxiety scale of pregnancy and Beck anxiety inventory. It explains that there is a significant effect of anxiety on primigravida women's decision of the vaginal mode of delivery according to the Anxiety scale of pregnancy $\left(\mathrm{F}=5.4143^{*}\right.$, $\mathrm{p}=0.024)$. On the other hand, there is no significant effect of anxiety on primigravida women decision of cesarean section $(\mathrm{F}=0.002, \mathrm{p}=0.962)$. Furthermore, the table shows that anxiety has a significant effect $\left(\mathrm{F}=6.289^{*}, \mathrm{p}=0.013\right.$ and $\mathrm{F}=9.658^{*}, \mathrm{p}=0.002$ respectively) on the decision regarding both vaginal delivery and cesarean section according to the Beck anxiety inventory

Figure (1): Shows total score of the studied primigravida women's fear of childbirth, where $(36.3 \%)$ has high level of fear, (46.3\%) has moderate level, and $(17.5 \%)$ has low level of fear of childbirth.

Figure (2): Shows total score of the studied primigravida women's decision of the preferred mode of delivery $(n=240)$. It displays that $39.2 \%$ decided vaginal delivery as a preferred mode, while $60.8 \%$ CS deliveryas a preferred mode with Mean \pm SD. $=12.57 \pm 2.55$ and $14.87 \pm 3.17$ respectively 
Table (1):Percent distribution of the socio-demographic characteristics of the studied primigravida women $(n=240)$.

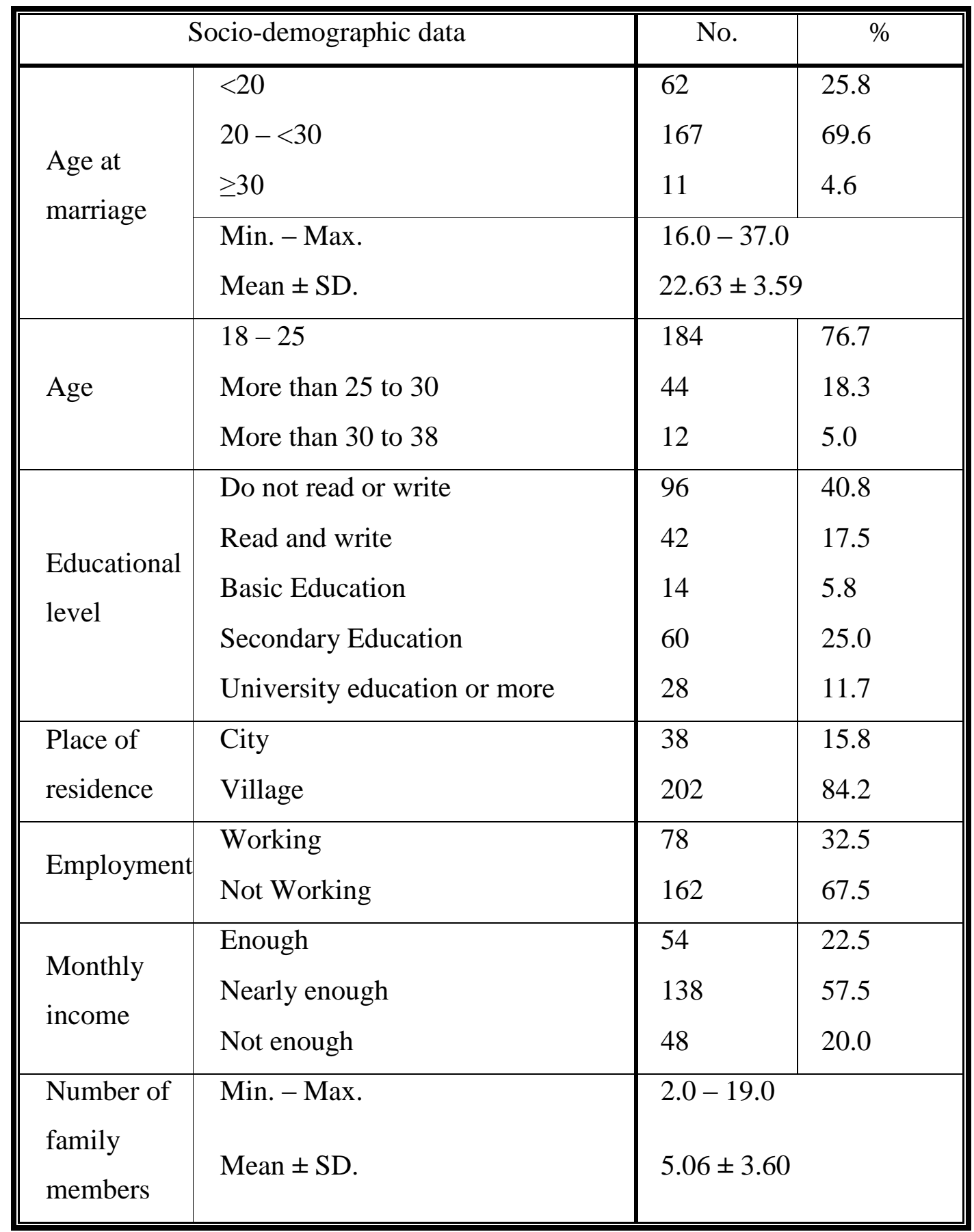

*Significant $(\mathrm{P}<0.05)$ 
Table (2): Total score of the studied primigravidawomen's anxiety of childbirth according to anxiety scale of pregnancy $(n=240)$.

\begin{tabular}{|l|l|c|}
\hline Total score of the studied & No. & $\%$ \\
primigravidawomen's anxiety of childbirth & & \\
according to anxiety scale of pregnancy & 10 & 4.2 \\
\hline Total score & 187 & 77.9 \\
Mild anxiety (8-15) & 43 & 17.9 \\
Moderate anxiety) (16-25) & $11.0-35.0$ \\
Severe anxiety $(26-63)$ & $22.12 \pm 3.96$ \\
\hline Min. - Max. & $26.19-83.33$ \\
Mean \pm SD. & $52.67 \pm 9.43$ \\
\hline \% Score & & \\
Min. - Max. & & \\
Mean \pm SD. & & \\
\hline
\end{tabular}

Table (3): Total score of the studied primigravida women's anxiety of childbirth according to Beck anxiety inventory $(n=240)$

\begin{tabular}{|c|c|c|}
\hline $\begin{array}{l}\text { Total score of the studied primigravida women's } \\
\text { anxiety of childbirth according to Beck anxiety } \\
\text { inventory }(n=240) \text {. }\end{array}$ & No. & $\%$ \\
\hline Low anxiety $(0-20)$ & 2 & 0.8 \\
\hline Moderate anxiety (21-33) & 119 & 49.6 \\
\hline High level of anxiety $(\geq 34)$ & 119 & 49.6 \\
\hline Min. - Max. & \multicolumn{2}{|c|}{$12.0-53.0$} \\
\hline Mean \pm SD. & \multicolumn{2}{|c|}{$34.08 \pm 6.35$} \\
\hline \multicolumn{3}{|l|}{$\%$ Score } \\
\hline Min. - Max. & \multicolumn{2}{|c|}{$20.0-88.33$} \\
\hline Mean $\pm \mathrm{SD}$ & \multicolumn{2}{|c|}{$56.81 \pm 10.58$} \\
\hline
\end{tabular}


Table (4):Multivariate linear regression for prediction of the effect of fear of childbirth on primigravida women's decision on the mode of delivery

\begin{tabular}{|c|c|c|c|c|c|c|c|}
\hline $\begin{array}{c}\text { Effect of fear of } \\
\text { childbirth }\end{array}$ & $\mathrm{B}$ & Beta & $\mathrm{t}$ & $\mathrm{p}$ & $\mathrm{R} 2$ & $\mathrm{~F}$ & $\mathrm{P}$ \\
\hline Vaginal delivery & 0.196 & $0.141^{*}$ & $2.195^{*}$ & $0.029^{*}$ & 0.020 & $-4.817^{*}$ & $0.029 *$ \\
\hline Cesarean section & -0.085 & -0.055 & 0.851 & 0.396 & 0.003 & 0.723 & 0.396 \\
\hline
\end{tabular}

Table (5): Multivariate linear regression for prediction of the effect of anxiety of childbirth on the studied primigravida women's decision on the mode of delivery according to anxiety scale of pregnancy and Beck anxiety inventory

\begin{tabular}{|c|c|c|c|c|c|c|c|}
\hline $\begin{array}{l}\text { Effect of anxiety of } \\
\text { childbirth }\end{array}$ & B & Beta & $\mathrm{t}$ & $\mathrm{p}$ & $\mathrm{R} 2$ & $\mathrm{~F}$ & $\mathrm{p}$ \\
\hline \multicolumn{8}{|c|}{ Anxiety scale of pregnancy } \\
\hline Vaginal delivery & -0.219 & -0.145 & $2.268^{*}$ & $0.024 *$ & $0.021 *$ & $5.4143^{*}$ & $0.024 *$ \\
\hline Cesarean section & -0.005 & -0.003 & 0.048 & 0.962 & $0.001 *$ & 0.002 & 0.962 \\
\hline \multicolumn{8}{|l|}{ Beck Anxiety Inventory } \\
\hline Vaginal delivery & 0.215 & 0.160 & $2.508^{*}$ & $0.013 *$ & $0.026^{*}$ & $6.289 *$ & $0.013 *$ \\
\hline Cesarean section & 0.296 & 0.197 & $3.108^{*}$ & $0.002 *$ & 0.039 & $9.658 *$ & $0.002 *$ \\
\hline
\end{tabular}

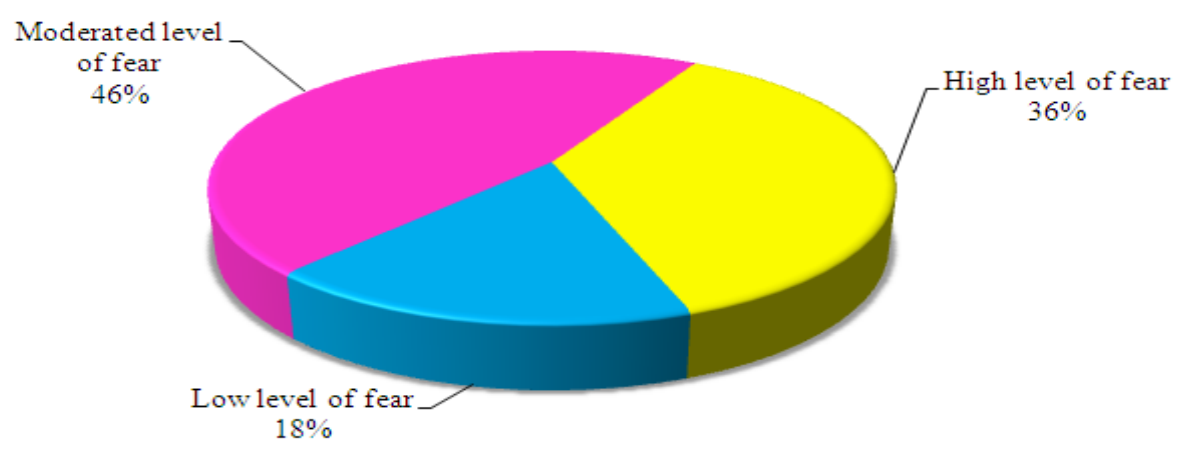

Figure (1): Total score of the studied primigravida women's fear of childbirth 


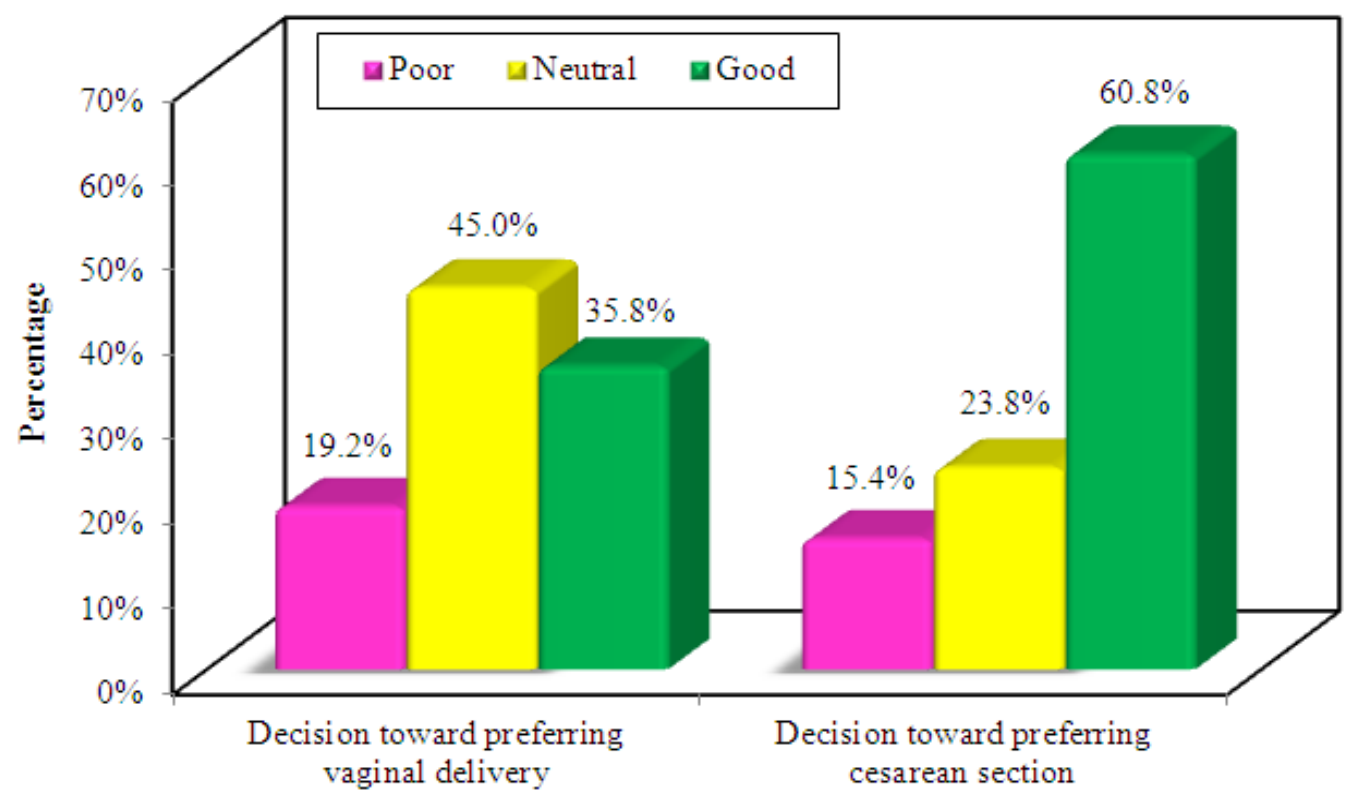

Figure (2): Total score of the studied primigravida women's decision on the preferred mode of delivery 


\section{Discussion}

Fear of childbirth (FOC) is negative perceptions that may be encountered during the antenatal, natal and postpartum periods and negatively affect the mother and her child. Primigravida fear of childbirth can affect their decision regarding the mode of delivery and requesting an elective caesarean section without medical indications. Scarce researches exist in this area. Consequently, this study was made to assess primigravida women's fear of childbirth and its effect on their decision regarding the mode of delivery ${ }^{(37)}$.

To conduct this study, a descriptive research design was adopted at 3 outpatient clinics of Obstetric and gynecological departments of Tanta University Hospital and El-Menshawy and Kom Hamade General Hospitals affiliated to Ministry of Health and Population Egypt. Convenient subjects of 240 women (80 from each hospital) were recruited based on the inclusion criteria of this study. Five tools were used by the researcher to obtain the necessary data about the study.

The results of the present study revealed that concerning the socio-demographic characteristics of the studied pregnant women, the age of majority of them ranges from 19-25 years, and were from rural areas, two fifth do not read or write and slightly more than two thirds do not work. This is in line with Suzer Ozkan and Demirc(2018) who advanced that a mean age $\pm \mathrm{SD}=25 \pm 3.2$ years, most had married at the age of 19-22 with the median age for marriage was 21 years, and half of them were housewives ${ }^{(38)}$. The present study also agrees with BakilanAbali (2016)who demonstrated that the mean age \pm SD of the participants $=27.02 \pm 5.02$. Additionally, $45.4 \%$ were primary school graduates, $87.4 \%$ were housewives, $67.1 \%$ had an income equal to their expenses, and $83.4 \%$ had a nuclear family ${ }^{(37)}$.

This study also agrees with the study conducted by Mohamed et al.(2019) who observed that primigravida women' were mostly between $22<26$ years with a range of 18 - 33 years, and a mean age $\pm \mathrm{SD}=$ $19.10 \pm 8.68,39.0 \%$ had secondary school education, and $80.0 \%$ were rural residences. On the other hand, their study contradicted with the present study with regards to occupation as they pointed out that slightly more than two thirds of the primigravidas had occupation ${ }^{(39)}$.

Related to the total score of level of fear of childbirth encountered among the studied primigravidas, the results of the present study revealed that nearly two fifths had high level, about one half had moderate level, and nearly one fifth had low level of 
fear of childbirth. This is in agreement with TirusetGelaw (2020) who proved that $(25.3 \%)$ had a high degree fear, $(39.8 \%)$ had a moderate degree, and $(10.3 \%)$ had a low degree fear of childbirth (134). On the other hand, Onchong (2020)found that approximately $29.5 \%$ had low, $40.4 \%$ moderate, $22.1 \%$ high, and $8 \%$ recorded severe FOC levels. Comparing by parity, the prevalence of severe FOC was higher on primigravida at $13.8 \%$ than multigravida $^{(40,41)}$.

Regarding the studied pregnant women's total score of level of childbirth anxiety according to anxiety scale of pregnancy, the present study shown that nearly four fifths had moderated level, and about one fifth had severe level and (4\%) had mild level of anxiety with a mean $\pm \mathrm{SD}=52.67$ \pm 9.43. These results are supported by SouazaandNairy(2015) who stated during the first trimester $(48.6 \%)$ of the studied pregnant women reported moderate degree, and $(48.4 \%)$ had severe degree of anxiety, while during the third trimester (71\%) had moderate degree, and (29\%) had severe degree of anxiety ${ }^{(42) .}$

Relating to total score of level of the studied pregnant women's anxiety of childbirth according to Beck anxiety inventory, the present study illustrated that almost one half had high level, and another almost one half had moderate level, while only less than one percent had low level of anxiety with a mean $\pm \mathrm{SD}=(34.08 \pm$ 6.35). These findings are supported by Mehmet Aksoyetal.(2014) who demonstrated that $40.8 \%$ of the pregnant women had severe anxiety level ${ }^{(43)}$. The present study is also in agreement with a study conducted in Egypt by Elzeblawyetal.(2017) who reported that (76.7\%) of the pregnant women suffered several levels of anxiety $(46.0 \%)$ in BeniSuef, (84.0\%) in El-Fayoum and $(100.0 \%)$ in Benha ${ }^{(44)}$.

Relating to the total score of the studied primigravida women's decision on the preferred mode of delivery, the present study displays that nearly two fifths decided vaginal delivery as a preferred mode, while slightly more than three fifths preferred CS delivery with a mean $\pm \mathrm{SD}$. $=$ $12.57 \pm 2.55$ and $14.87 \pm 3.17$ respectively. These results agree with Al-Diwan, and Mehedi(2019) who stated that the cesarean section rate in the primigravida women was much higher than the ideal rate recommended by the World Health Organization $^{(45)}$.

Regarding the multivariate linear regression of the effect of fear of childbirth on primigravida women's decision on the mode of delivery, the present study revealed that fear of childbirth has a significant effect on the decision of 
primigravida women toward normal vaginal delivery where $\left(\mathrm{F}=-4.817^{*}\right.$, $\mathrm{p}=0.029$ ), while there it had no significant effect on their decision toward cesarean section mode of delivery $(\mathrm{F}=0.723$, $\mathrm{p}=0.396$ ). This may be due to fear of pain, painful event due to new experience, uterine contractions, recurrent vaginal examinations, and vaginal lacerations, and poor information about labor pain and pain management ${ }^{(46)}$.

Additionally, regarding the multivariate linear regression for prediction of the effect of anxiety of childbirth on the studied primigravida women's decision on the mode of delivery according to anxiety scale of pregnancy and Beck anxiety inventory, the present study confirmed that there is a significant effect of anxiety on primigravida women's decision of the vaginal mode of delivery according to the Anxiety scale of pregnancy, while there is insignificant effect on their decision of the cesarean section mode $\left(\mathrm{F}=5.4143^{*}\right.$, $\mathrm{p}=0.024$ and $\mathrm{F}=0.002, \quad \mathrm{p}=0.962$ respectively). Furthermore, according to the Beck anxiety inventory, anxiety has a significant effect on the decision regarding both vaginal delivery and cesarean section modes of delivery $\left(\mathrm{F}=6.289^{*}, \mathrm{p}=0.013\right.$ and $\mathrm{F}=9.658^{*}, \mathrm{p}=0.002$ respectively).

The previous results are also supported by

Rakshaet al. (2017) who found that majority of normal vaginal delivery and caesarean section were experiencing moderate anxiety due to different factors both in normal vaginal delivery and caesarean section. In normal vaginal delivery $95 \%$ of the cases experienced anxiety due to "stressful life events" and fear of changes in the breast and in the body weight, while in caesarean section $75 \%$ experienced anxiety attacks and fear of effect on sexual relation. The level of anxiety was higher in case of caesarean section compared to normal vaginal delivery with a mean score of 24.85 and 20.35 respectively $^{(47)}$.

Finally this study addressed that fear of childbirth is a key aspect of primigravida women health and quality of care, which is greatly neglected. Primigravidas are in critical need comprehensive high quality, sensitive, and respectful care to reduce their fear and anxiety of childbirth and improve their decision on the mode of delivery. They are also in need for more attention, counseling, health education, investigations, reassurance, and good antenatal booking, and engagement in decision-making toward mode of delivery, to improve their psychological and physical condition, reduce the rate of elective cesarean section and increase rate of normal vaginal delivery. Additionally, there is a need for hospital politics to 
control mode of delivery that may be performed against the real choice of the primigravida women.

\section{Conclusion}

- Majority of the studied primigravida women were at age group of 18-25 years, do not read and write, not working and from rural areas and attended antenatal care classes in private clinics.

- Majority of the studied primigravida women experienced different levels of fear of childbirth, considering that nearly two fifth of them had high level of fear.

- Majority of the studied primigravida women experienced different levels of anxiety of childbirth, considering that nearly one fifth of them had severe anxiety according to anxiety scale of childbirth, and nearly one half of them had high level of anxiety according to beck anxiety inventory.

- Majority of the studied primigravida women decided cesarean section as a preferred mode of delivery, compared to slightly more than one third of them who decided vaginal delivery as a preferred mode of delivery.

\section{Recommendations}

Based on the findings of the current study, the following recommendations are derived and suggested

- Comprehensive antenatal care should be provided to all pregnant women, especially primigravida who are considered high-risk groups to alleviate their fear of childbirth for better maternal and fetal outcomes.

- Psycho-educational nursing intervention should be generalized for all primigravida women to reduce their fear of childbirth and enhance their physical and psychological wellbeing and overall childbirth experience.

- Nurses should be trained on giving counseling to all pregnant women, especially primigravidas to enhance their knowledge and attitude regarding normal mode of delivery.

- Primigravidas' husbands or partners should be encouraged to participate in the antenatal classes to support them and alleviate their fear and anxiety, as well as to provide a more positive experience about pregnancy and childbirth experience.

- Written hospital policies should be legislated to criminalize doing C.S. without medical indication in order to 
safe clients' money and to improve maternal and fetal outcome.

- Structural, organizational and conceptual changes in obstetric care are needed to pregnant women with fear of childbirth, alongside the need for evidence-based information about non-medical and medical pain- relief.

- Decision-making aids for provision of a continuity model of midwifery care that include strategies to prevent fear of childbirth are important.

- Written policies, guidelines and protocol of care should be developed for improving antenatal care that should be provided to pregnant women from nursing and midwifery personnel about everything from beginning of pregnancy till postpartum period.

- Increase women's awareness about their rights of quality antenatal nursing care and proper health education to prevent their fear of childbirth and to make informed decisions regarding the mode of delivery.

- Other researches could be done to identify nurses' knowledge about management of fear and anxiety of childbirth and the effect of health education about fear and anxiety of childbirth on maternal and fetal outcome.

\section{References}

1-Phobia.Available at: https://en.wikipedia.org/wiki/Phobia.

Retrieved at: 25/12/2020

2-Khamehchian M, Adib-HajbagheryM. Primiparous women's experiences of normal vaginal delivery in Iran: a qualitative study. BMC Pregnancy Childbirth. 2020; 20(1): 259.Availablefrom: $\quad 10.1186 / \mathrm{s} 12884-$ 020-02954-4

3-Dutta DC.Textbook of Obstetrics. 9th ed., London:Jaypee Brothers com.; 2018. $108-15$

4-Azimi M., Fahami F., MohamadiriziS.The relationship between perceived social support in the first pregnancy and fear of childbirth. Iran J Nurs Midwifery Res. 2018;23(1):235.Available at: https://www.ijnmrjournal.net/article.asp ?issn=17359066; year $=2018$; volume $=23$ ;issue $=3$; spage $=235$; epage $=239$; aulast $=$ Azimi

5-Egypt Demographics Profile 2019.Available at: http://www.tradingeconomics.com/egyp t/birth-rate-crude-per-1-000-people-wbdata.htm, Retrieved at: 20-12-2019.

6-Population council2018 .Available at: https://www.popcouncil.org/uploads/pd 
fs/2018PGY_CesareanSectionEgypt.pdf

. Retrieved at: 5-10-2020

7-Berlington M, Munkhondya J, Tiwonge

E. Efficacy of companion-integrated childbirth preparation for childbirth fear, self-efficacy, and maternal support in primigravid women in Malawi. BMC Pregnancy and childbirth. 2020.Available

at:https://bmcpregnancychildbirth.biom edcentral.com/articles/10.1186/s128

8-Boryri T, NavidianA, Marghzari N. Comparison of the effect of muscle relaxation and guided imagery on happiness and fear of childbirth in primiparous women admitted to health care centers. International Journal of Women's Health and Reproduction Sciences. 2019; 7(4): 490-495. Available at: http://www.ijwhr.net4019-2717-5

9-Lundgren I, NilsonK. Previous birth experience in women with intense fear of child birth .Journal of Obstetric Gynecologic \& Neonatal Nursing.2010; 39(3):298-309. Available at: https://www.researchgate.net/publicatio n/44798166_Previous_Birth_Experienc e_in_Women_With_Intense_Fear_of_C hildbirth

10- Edman G,Ryding, E. Expectation and experiences of childbirth in primipara with caesarean section. International
Journal of Obstetrics \&Gynaecology. 2008; 115(3):324-331.

11- Pasha H, Faramarze M. The role of social support in predication of stress in pregnancy.Available at:JBUMS 2015, 17(11): 52-60. http://jbums.org/browse.php?a_id=533 $4 \&$ sid=1\&slc_lang=en . Retrieved at:21-3-2020

12- Nazare S, Salare P, Mazlom R, Mehram F. The comparative study of social support postpartum mothers multiparity in the first and second month after delivery. Public Health Research Khorasa. 2014;8(1):1-9.

13- EL-Malky E, El-HomosyS, Shehad A. Effectiveness of antenatal nursing intervention on childbirth's fears, Psychological - wellbeing and pregnancy outcomes in primipara's women. Journal of Nursing Science. 2018; 4(2):17-24. Available at :http://www.aascit.org/journal/jns.

Retrieved at: 28-3-2020.

14-Zahede M, Asemane O, Mahmodyan H. Given the role of medical in assistants in reducing caesarean sections; designed and evaluated the psychometric questionnaire to measure attitudes of residents towards elective caesarean sections and vaginal births. Iranian Journal of Medical Ethics and History. 2015;8(1):59-71. 
15-Craig A. Smith \& Richard S, Lazarus. Theory and research. Handbook of personality. emotion and adaptation. Chapter 23 In L. A. Pervin (Ed). (1990); 609-637.

16-Ibrahim N, Hanafiah F, Osman Z. Fears related to pregnancy and childbirth among primigravidae who requested caesarean versus vaginal delivery in Iran. Maternal Child Health Journal. 2016; 8(18):266-379. Available at: https://www.researchgate.net/publication

17- Bhatia MS, Jhanjee A. Tokophobia: A dread of pregnancy. Ind. Psychiatry J. 2012; 21(2):158-9.

18- Michelle G, Allison M. Panic disorder, phobias, and generalized Anxiety disorder. Annual review of clinical psychology. 2005;1 (1): 197225.Available at:

10.1146/annurev.clinpsy.1.102803.14 3857

19-NakazibweW. Exploring the psychological factors affecting the participation of pregnant women in physical activities in Uganda.PublishedMaster's Thesis in Sport and Exercise Psychology.Spring 2016.Department of Sport Sciences University of Jyvaskyla.Available at:https://jyx.jyu.fi/bitstream/handle/1 23456789/50222/5/URN-NBN-fi-jyu- 201606092985.pdf, Retrieved at:21-52020.

20- Çankaya S, Şimşek B. Effects of antenatal education on fear of birth, depression, anxiety, childbirth selfefficacy, and mode of delivery in primiparous pregnant women: A prospective randomized controlled study. Clinical Nursing Research.2020;Available at: 18-72020.

https://doi.org/10.1177/105477382091 6984.

21- Lalmeena B. A Study to assess the anxiety related to the onset of labor and delivery among primigravida mothers admitted for delivery at the selected hospital, Jaipur, Rajasthan.International Journal of Nursing and Medical Investigation.2018;2656-4656.

Available

at::http://innovationalpublishers.com/J ournal/ijnmi. Retrieved at: 19-122019.

22-Lovejoy M. Disturbances in the social body: Differences in body image and eating problems among African American and white women. Gender \& Society.2011;15(2):239-261.

23- DonelJ .Tocophobia: Overwhelming fear of pregnancy and childbirth.International Journal of 
Reproduction Contraception

Obstetricsand Gynecology. 2019 Nov;8(11):4641-4645.

DOI:

http://dx.doi.org/10.18203/2320-

1770.ijrcog20194915

24- Egypt Service Provision Assessment Survey. 2004. Ministry of Health and Population Cairo, Egypt. ElZanatyAssociates.ORC Macro Calverton, Maryland, USA.2015.

25-Moore K,ReganM,Katie G. Choice? Factors that influence women's decision making for childbirth. The Journal of Perinatal Education (Advancing Normal Birth).2017; Available

at:https://www.researchgate.net/public ation/262680627.

26- Bayrak E, Kaymaz O. Caesarean delivery or vaginal birth: Preference of Turkish pregnant women and influencing factors. J Obstet.Gynaecol. 2010; 30(2):155-165.

27-Wen Chen S, Alison M,Tracey K. Women's decision-making processes and the influences on their mode of birth following a previous caesarean section in Taiwan: A qualitative study . BMC Pregnancy and Childbirth. 2018;18(1): 31. Available at: https://bmcpregnancychildbirth.biome dcentral.com/articles/10.1186/s12884018-1661-0
28- Preis H, Benyamini Y, Eberhard-Gran M .Childbirth preferences and related fears - comparison between Norway and Israel.BMC Pregnancy Childbirth. 2018 Sep;18(1):362. Doi: 10.1186/s12884-018-1997-5.

29- Khwepeya M, Huang HC, Lee GT, Kuo SY. Validation of the Wijma delivery expectancy/experience questionnaire for pregnant women in Malawi: A descriptive, cross-sectional study.BMC Pregnancy Childbirth. 2019. Aug;20(1):455. Doi: 10.1186/s12884-020-03146-w.

30-Mortazavi F, Akaberi A . Validation of the anxiety scale for pregnancy in asample of Iranian women . International Journal of Women's Health and Reproduction Sciences $.2018 ; \quad 6(1): \quad 67-74$. Available at: file://C:/Users//GTC/Downloads/pdf IJWHR.pdf.

31- Sinesi A, Maxwell M, O'Carroll R .Anxiety scales used in pregnancy: Systematic review. CheyneH. BJPsych Open. 2019 Jan;5(1): e5. Doi: 10.1192/bjo.2018.75.

32-Beck A, Epstein N, Brown G, Steer A. An inventory for measuring clinical anxiety: Psychometric properties. Journal of Consulting and Clinical Psychology.1988; 56(1):893-897. 
33-Leyfer O, Ruberg L, BordenJ. Examination of the utility of the Beck Anxiety Inventory and its factors as a screener for anxiety disorders.Journal of Anxiety Disorders. 2006; 20 (4): $444-458$.

\section{4-Rabieipoor S, KhodaeiA} ,RadfarM,Khalkhali H. The relationship between husbands' participation in prenatal care and mental health of pregnant women referred to health centers in Urmia. J NursMidwUrmiaUniv of Med Sci. 2015;13(4):338-47.

35-Sharifirad G, JavaheriS,Mazaheri M.A survey on the effects of husbands' education of pregnant women on knowledge, attitude, and reducing elective cesarean section.Journal Education Health Promotion. 2013 Sep; 2(50-65):

36- Maharlouei N, Rezaianzadeh A, Kamran B. The preference of Iranian women to have normal vaginal or cesarean deliveries.Journal of Research in Medical Sciences. 2013; 18(11):943-950.

37- EgelioğluCetişli N, DenizciZirek V, Bakilan F. Childbirth and Postpartum Period Fear in Pregnant Women and the Affecting Factors. 2016 Available at:21-3-2020. http://dx.doi.org/10.5294/aqui.2016.16 .1 .5

38-SuaeroskanF,DemircN.

Factorsaffecting delivery preference of primigravida women: A qualitative study. TurkiyeKlinikleri J Nursing Science. 2018;10(2):103-14 DOI: 10.5336/nurses.2017-57649.

39- Mohamed M, Elsayed M, Mahmoud T. Anxiety and fear level toward childbirth among primigravida versus multigravida. Journal of Nursing and Health Science (IOSR-JNHS). 2019; 8(2):36-44). Available at: 0802023644www.iosrjournals.org.

40-Gu C, Zhu X, Ding Y, Setterberg S, Wang X, Tao $\mathrm{H}$, et al. A qualitative study of nulliparous women's decision making on mode of delivery under China's two-child policy.Midwifery. 2018; 62(1):6-13.

41-Thaler I, Manor D, Itskovitz J, RottemS,Levit N. Changes in uterine blood flow during human pregnancy. American Journal of Obstetric and Gynecological. 1999; 162(1):121-5.

42- Souaza M, Nairy KS. Prevalence of pregnancy anxiety and associated factors .International Journal of Africa Nursing Sciences. 2015; 3(1): 17.Available at: https://doi.org/10.1016/j.ijans.2015.06. 002. 
43-Mehmet Aksoy M, NurAksoy A, DostbilA.Therelationship between fear of childbirth and women's knowledge about painless childbirth. Obstetrics and Gynecology International .2014; Available at: 11-22020.http://dx.doi.org/10.1155/2014/2 74303.

44- Elzeblawy H, AbdElhaliem S, Thabet S. Disparities of prevalence and causes of maternal antenatal anxiety among primigravida pregnant women in Egypt. American Research Journal of Nursing.2017;3(1): 15. Available at: 12-6-2020.

nona_nano_1712@yahoo.com.

45- Al-Diwan J,MehediM.Cesarean section rate in a sample of primigravida women in the public Maternity Hospital in Erbil City, Iraq. International Journal of Women's Health and Reproduction Sciences.2018; 6(2): 150153.Available at:http://www.ijwhr.net. 46- Leifer G. Introduction to maternity \& pediatric nursing. 4th ed., Hong Kong: Saunders com.; 2003.183-4, 204-14.
47- Raksha G, Anjali T,Kirna T. An exploratory study to assess the factors causing anxiety among primigravida planned for normal vaginal delivery and caesarean section admitted at Mata Kaushalya Hospital. Maternal and Pediatric Nutrition Journal.2017; 3(1).DOI: 10.4172/2472-1182.1000122 